gynaecological treatment in district 3, about $3 \%$ had had to wait for more than a year (the Hospital Activity Analysis figure), which contrasts with a " $42 \%$ risk" of waiting for more than a year after placement on the list, which the SBH 203 figure might erroneously be taken to imply.

It should also be noted that the use of the census figures as a basis for "shopping around" between districts" may sometimes be misleading. If a prospective patient for gynaecological treatment in district 3 were referred to district 1 for a shorter wait on the basis of comparing the SBH 203 figures she would in fact be twice as likely to have to wait for more than a year than if she were placed on the waiting list in district 3 .

The SBH 203 and Hospital Activity Analysis figures are not comparable in several respects. Firstly, by definition, data from the Hospital Activity Analysis relate to the full time between placement on the list and admission while the census figures relate only to the time waited so far (neither include the time waited from initial referral to placement on list). Secondly, the census figures probably include patients who will never be admitted from the waiting listfor example, those who are admitted as emergencies or die before their elective admission would have occurred. ${ }^{4}$ Thirdly, no data of placement on the booking list is recorded in the Hospital Activity
Analysis; thus booked admissions, included in the SBH 203 shown in the table, cannot be included in the Hospital Activity Analysis figures. Booked cases, however, made up only about one tenth of elective admissions in the districts described. They are unlikely materially to affect the patterns of waiting shown in the table and do not affect the principles illustrated by the figure. The main difference between the measures of waiting times given by SBH 203 and those given by the Hospital Activity Analysis is the distinction between the census measures and the event measures illustrated in the figure.

\section{References}

1 Department of Health and Social Security. Reduction of waiting times for in-patients admission: management arrangements. London: DHSS, 1975. (HSC (1S)181.)

2 College of Health. The College of Health guide wo hospital waiting lists. 2nd ed. London: Victoria Park Publications, 1985.

3 MacMahon B, Pugh TH. Epidemiology: principles and methods. Boston: Little, Brown and Co, 1970:65.

4 Lee A, Don B, Goldacre MJ. Waiting list statistics. II. An estimate of inflation of waiting list length. BrMed J 1987;295:1197-80.

(Accepted 11 August 1987)

\title{
Research Policy
}

\section{Why do research and which research to do?}

\author{
RICHARD SMITH
}

People do research largely because "it turns them on, because it's there." They often cannot say more exactly why they do it, but rarely is it for financial reward or for Freud's "fame and the love of beautiful women." There are much quicker routes to such rewards. Research can be highly creative, rewarding, and exciting but also intensely frustrating. Those who commit their lives to it are varied, mercurial, brilliant, and strong and single minded, and, recognising this, the policy of many of those funding research (including the Medical Research Council' ${ }^{1}$, has been to spot brilliant researchers and let them do what they want.

Just this year Johnson and Johnson have given Sir James Black, the scientist who discovered $\beta$ blockers and cimetidine, what Sir James calls "distortion free funding." The company will play no part in directing the research but will have first refusal on any products that emerge. Sir James believes that big fanfares and publicity drives interfere with the process of research. Attempts by those who fund research to be too directive may backfire.

Yet governments the world over are becoming much more interested in managing and directing research, ${ }^{3}$ and Britain is no exception. Here I look at why the government and some of the funding bodies support research and at which categories of research they choose to support. These bodies can usually answer the question, "Why do research?" more explicitly and confidently than the people who actually do it. Whether the official bodies can transmit their reasons to the researchers themselves is more doubtful.

British Medical Journal, London WC1H 9JR

RICHARD SMITH, BSC, MB, assistant editor

\section{Why the government supports research}

The government's standard reasons for supporting research were given most recently in its response to the House of Lords Select Committee on Science and Technology's report on civil research and development"; "Public expenditure on science and technology serves various government objectives: the advancement of knowledge, support for policy for formulation and implementation, improvement of technology, improvement of health and the environment, support for procurement decisions and support for statutory duties." These reasons are expanded in an annex to the Annual Review of Government Funded RED (see box) ${ }^{6}$ and in the review the government goes so far as to break down its overall expenditure ( $\$ 4582 \mathrm{~m}$ in $1985-6$ ) according to purpose (fig 1 ).

Comparing the breakdown of expenditure by purpose and where the money actually goes (fig 2 ) gives an idea of the government's real priorities. Obviously defence is at the top, and the Ministry of Defence does no research that the government categorises as basic (see box). Although the British government now spends a much higher proportion of its research funds on defence than most other countries, ${ }^{7}$ the history of government interest in science shows clearly that the military possibilities are usually what first prompts most governments to invest in research. ${ }^{8}$ The first government ever to invest in scientists was the revolutionary government that took power after the French revolution, and the first job of the Committee of Four Citizens was to seek out new methods of defence. More recently it was experience with developing the atomic bomb that led the American government to invest heavily in research for the first time.

The next priority of the British government in conducting research is economic, and the government said in its response to the 


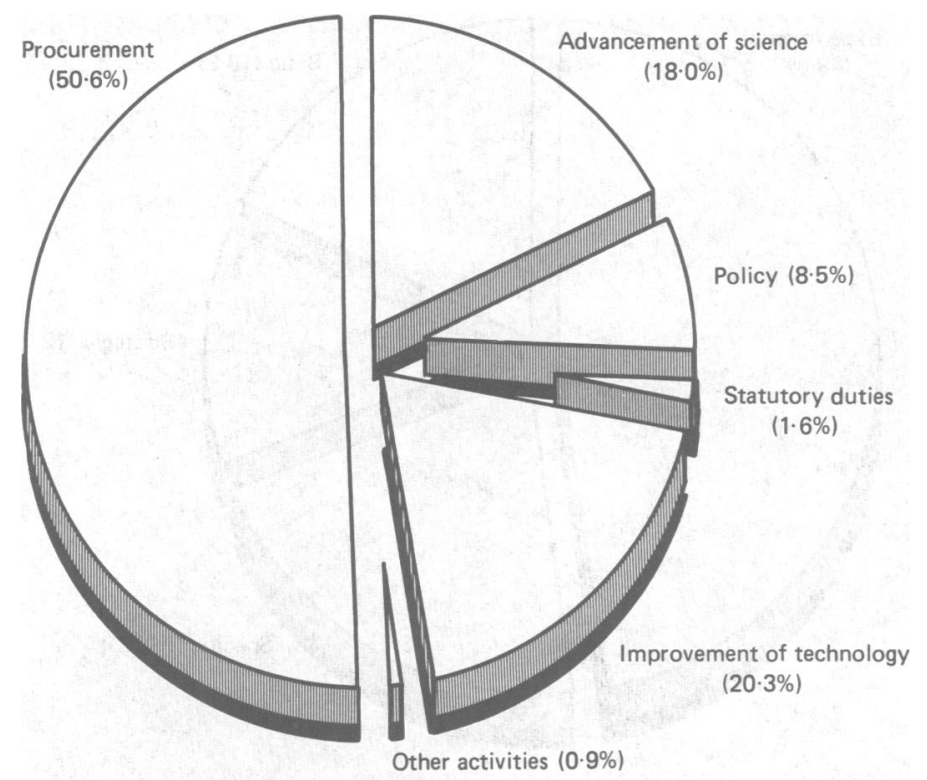

FIG 1-Percentage of government expenditure on research and development devoted to different purposes in 1984-5.

House of Lords select committee that its support for basic science in the universities "is intended to lead to the development of knowledge and acquisition of skills; these have a major impact on the United Kingdom's economy and position in world markets." (Interestingly this conflicts with the Treasury's evidence to the committee: it argued that there was no direct relation between expenditure on research and development and the health of the economy. ${ }^{4}$ ) Basic university science is thus valued primarily for its economic potential, and the heart of the government's policy on scientific research is given in the next sentence: "It should be a national priority to focus the effort of the scientific community and industry on increasing the economic effectiveness of our national investment in science and technology." The same paragraph also says how this will be done: "A key consideration is effective management."s

\section{Categorising research}

The government also now categorises research, and to do this it follows the Frascati definitions devised by the Organisation for Economic Cooperation and Development.' These standard definitions have allowed science policy researchers to make international comparisons and to begin to measure the "effectiveness" of investing in various sorts of research. But research-rather like creative artistic endeavour-resists easy categorisation, and, furthermore, governments tend to adapt the definitions. The second box shows the British government's definitions of basic, strategic, and specific research, and experimental development. ${ }^{6}$ Figure 3 shows how much the government spends on each sort of research, and fig 4 shows which divisions do which sort of research. Again defence dominates.

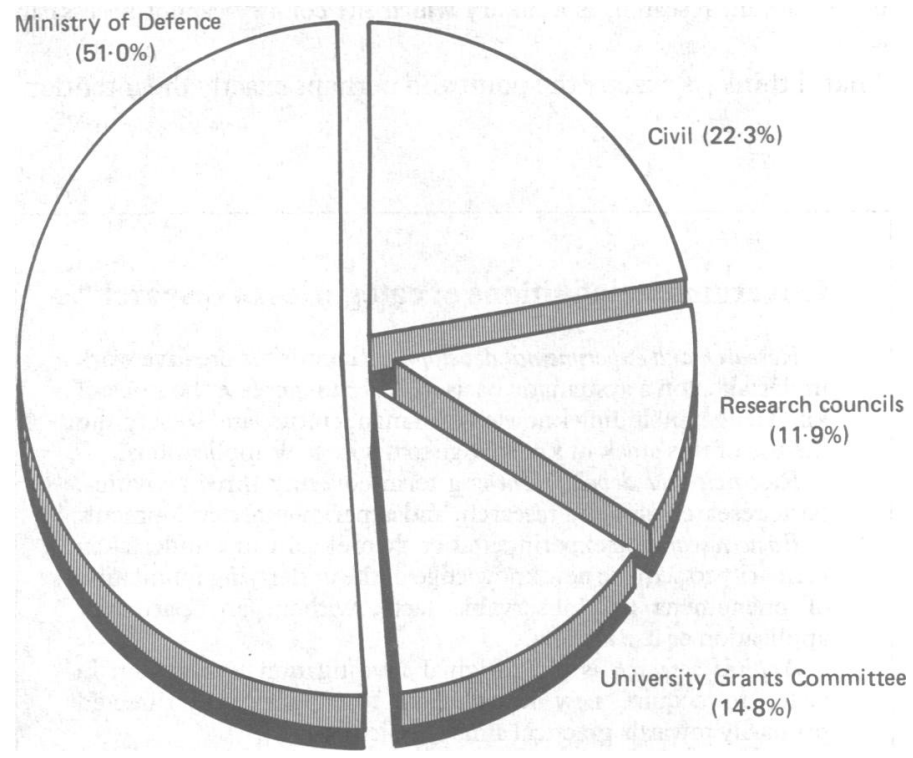

FIG 2-Distribution of government expenditure on research and development through different channels in 1984-5.

\section{Purposes of government research and development *}

\section{Advancement of science}

Work funded primarily in order to increase human knowledge-that is, to advance scientific understanding of natural phenomena. This research contributes to the scientific base of the nation and, although originally funded with no specific application in view, much of it eventually results in long-term benefit through the eventual application of knowledge gained.

\section{Support for policy formation and implementation}

Applied research (some of which may be strategic in nature), and experimental development carried out in order to meet government's own needs for knowledge or improved products of processes, for example:

- to identify and assess policy options (for example, on choice of renewable energy resources, to identify measures to deal with social or environmental problems);

- to facilitate forward planning (for example, on the efficient use of the radio spectrum);

- to make the provision of Government services (for example, defence, health etc) more effective and efficient.
3 Improvement of technology

Applied research and development funded by government departments but often carried out within industry, to advance the technology of different sectors of the United Kingdom economy - manufacturing, agriculture and construction industries etc. Again, some of the research may be strategic in nature.

\section{Support for procurement decisions}

Applied research and development which contributes to the specification and development of goods and services required by departments (mainly related to defence needs), and to equip the purchasing department to act as an informed buyer.

\section{Support for statutory duties}

Applied research and development which assists departments to carry out statutory responsibilities or other obligations (for example, in connection with the Health and Safety at Work Act or Building Regulations).

6 Support for other activities

Applied research and development which cannot be classified under the other headings (for example, research to support economic or agricultural progress in developing countries). 
Applied research has been split into strategic and specific research, and this new strategic research is the one to watch. (In the original Frascati definitions strategic research is a division of basic rather than of applied research; the fact that-unlike many other countries, including Japan-Britain chooses to make it a division of applied research must reflect the British government's anxiety to see economic benefit from its research.) Both the House of Lords select committee and the government in its response to the committee are concerned about "strategic research which is of most significance to the United Kingdom's economic future." Both are keen to put more money into strategic research, and that money is likely to come from the basic science budget. Indeed, that is already happening, and the Advisory Board for the Research Councils smells a rat:

The distribution between basic and strategic research is however not particularly helpful for making policy. It erroneously suggests that a clear boundary can be drawn between purely "curiosity-oriented" and "relevant" research. It also encourages the idea that curiosity-oriented, as opposed to more relevant research, is a luxury which the country cannot necessarily afford. ${ }^{10}$

That, I think, is exactly the point and perhaps exactly the intention.

\section{Government definitions of eategories of research ${ }^{\star}$}

Research and experimental development comprises creative work undertaken on a systematic basis in order to increase the stock of knowledge, including knowledge of man, culture and society and the use of this stock of knowledge to devise new applications.

Research and development is a term covering three activities: basic research, applied research, and experimental development.

Basic research is experimental or theoretical work undertaken primarily to acquire new knowledge of the underlying foundation of phenomena and observable facts, without any particular application or use in view.

Applied research is also original investigation undertaken in order to acquire new knowledge. It is, however, directed primarily towards practical aims of objectives.

Strategic research, therefore, is defined as applied research which is in a subject area which has not yet advanced to the stage where eventual applications can be clearly specified.

Experimental development is systematic work drawing on existing knowledge gained from research and practical experience that is directed to producing new materials, products or devices, to installing new processes, systems and services, or to improving substantially those already produced or installed.

^From Annual Review of Government Funded RE $D .^{6}$

\section{The House of Lords's policy for research}

The House of Lords select committee is proving to be important in shaping British science policy, which is why its report on biomedical research (expected early in the New Year) may prove crucial. Somebody from the Cabinet Office suggested to me that the House of Lords committee was in a way Britain's equivalent to the American Office of Technology Assessment. The job of scrutinising Britain's research effort is, I suspect, left so much to the House of Lords because it has considerable expertise on a subject that must be a closed book to many members of parliament.

In its last report the House of Lords committee gave its own policy for research, ${ }^{4}$ and it is more acceptable to academic researchers than the government's aims. The House of Lords puts at the top of its policy the pursuit of excellence: "Excellence in science and technology is vital in itself and because the excellent stimulate and teach others. Sustained mediocrity is a waste of resources. Funding must put the pursuit of excellence before uniformity."

This is a priority that the medical researchers I met would share. In this way research may be like acting or composing-only the

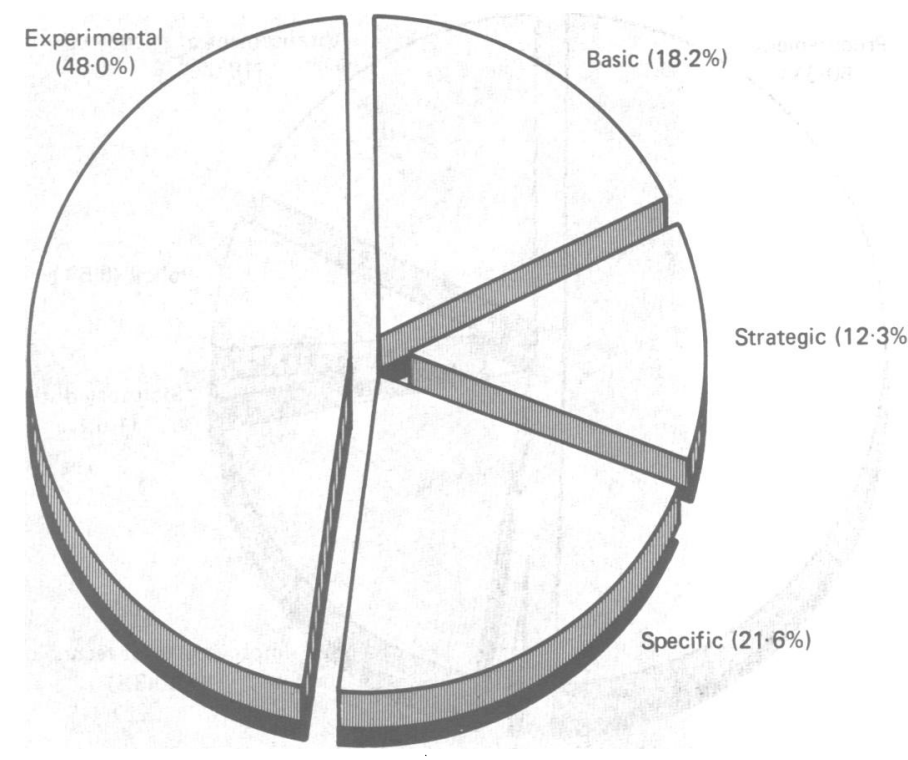

FIG 3-Percentage of government expenditure on research and development devoted to different categories in 1984-5.

excellent matters. The world is full of mediocre bank managers, government officials, teachers, doctors, and journalists; indeed, most people in most occupations are mediocre and they keep the world turning. But research, many researchers would argue, is different: you must either be excellent or you should be doing something else.

One problem with this policy is that in reality most researchers are not excellent-and even those who once were may cease to be so. Secondly, that the excellent are often not interested in subjects such as incontinence in the elderly, and a body-like the MRC-that concentrates on funding the excellent may do little on such important subjects. In this way health services research has consistently foundered. Thirdly, much of the research done by doctors is reviewing what they are doing and assessing new treatments-research that would not be classed as excellent and which might therefore go unfunded. Fourthly, hard evidence is lacking that the excellent can be reliably spotted or that funding a few excellent people will ultimately be more productive than funding many more who are not quite so excellent. This is one of the

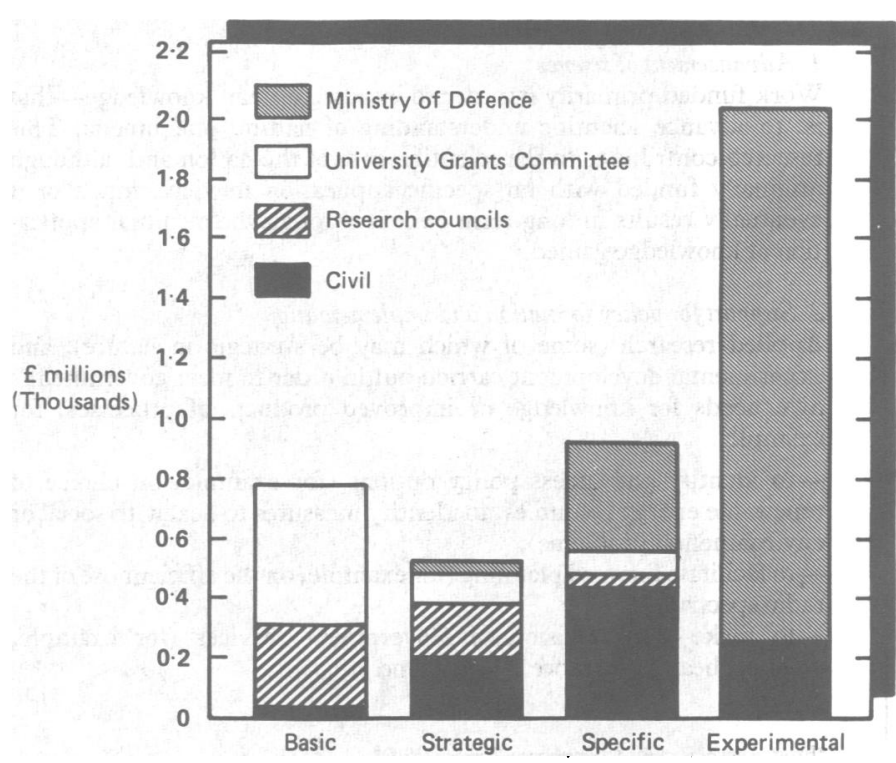

FIG 4 - Relative expenditure in 1984-5 on different categories of research through the Ministry of Defence, the University Grants Committee, the research councils, and civil research. 
many problems of science policy that is unanswered and almost, indeed, unstudied.

Many of the academics I met would, however, agree with the House of Lords committee that funds should be channelled towards the excellent and not frittered away on the mediocre. And many academics are suspicious that the government would rather support mediocre research that is likely to produce some economic benefit in the short term than excellent research that even if it does lead to economic benefit will do so only in the long term.

The House of Lords committee's second priority is a constant flow of skilled manpower, which must begin in primary schools, and its third priority is "a healthy foundation of basic research." "Assured programmes of strategic research" and "competitive industrial performance" come fourth and fifth. These, I think, are very much the priorities of scientists and those close to them rather than the priorities of politicians and managers remote from the actual process but anxious that the economy should be boosted. Scientists would also support the committee's first recommendation on means to achieve these objectives-"stable conditions for funding." Many of the researchers whom I met think that the increasing difficulty of getting long term funding is the main factor destroying morale among researchers.

\section{The priorities of the Advisory Board for the Research Councils}

The Advisory Board for the Research Councils, the body that advises government on the distribution of funds between the five research councils, has recently published its own criteria for scientific priorities." It acknowledges that "at the most detailed level of decision making - the selection of individual research proposals for grant support...-we would expect overriding weight to be given to intrinsic scientific criteria." Excellence must be the priority at this stage, but then the problem is how to introduce other criteria if you have only a limited number of excellent projects to choose between (and the truly excellent is usually in short supply). The other "internal criteria" of the advisory board are "timeliness-expectation of rapid scientific advance (in 5, 10, or 20 years)" and "pervasiveness-likelihood of a wide range of links with other research." These criteria are not so easily judged as excellence, and judging even that can be difficult.

The advisory board also has "external criteria" that it wants the research councils to use, and these are "exploitability - potential for nationally profitable industrial or commercial use (in 5, 10 or 20 years)"; "applicability - potential for uses leading to other benefits: social, environmental or related to government policy (in 5, 10, or 20 years)"; and "significance for education and training." Exploitability and applicability are buzz words among science managers, yet again methods for judging them are not proved. Interestingly, the advisory board puts economic benefits above social benefits and does not mention health-this is presumably subsumed into social benefits.

\section{The priorities of the Medical Research Council}

The aims and the priorities of the MRC are set out in its corporate plan, ${ }^{1}$ which the government and the Advisory Board for the Research Councils required it to produce. The reluctance with which it did so is almost palpable as you read the document, and Sir James Gowans, the recently retired secretary of the MRC, was well known to be prominent among those who valued greatly the autonomy of the research councils and resented the intrusion of "higher authorities." From this point of view, he must be glad to have retired.

The MRC has an easier task than the other research councils when it must state its aims and justify its existence. Most of today's important diseases-heart disease, cancer, dementia, psychiatric disorders, and the acquired immune deficiency syndrome (AIDS) - cannot be effectively treated and so research must be done to find ways of doing so. The research must cover, the plan says, the "preventive, social and environmental aspects of medicine as well as studies related to the cause, diagnosis and treatment of disease."

The MRC has always been heavily committed to basic research, and a former member of one of its committees suggested to me that much of the unhappiness with the MRC would be removed if it was renamed the Basic Medical Sciences Research Council. The corporate plan says, "Investment in long term basic research [is essential] because the history of important practical advances in medicine shows that the routes to discovery are often unpredictable." History is not quite as clear as the MRC might think on this issue. The analyses of routes to practical innovations show overall that they are unpredictable, but they do not agree on the importance of basic research. ${ }^{12}$ But, as Barton Dodd, an assistant secretary of the MRC said to me, with some problems there is nothing else to do except basic research. For instance, the MRC was criticised for not doing more work specifically on dementia, but what it did was to invest in basic neurosciences-and now the way of doing more work on dementia is becoming clearer.

In its corporate plan the MRC emphasises that over its entire 65 years its policy has been "'to recognise and back excellent individuals and to devise methods of support best suited to achieve their aims." Again the MRC calls on history (rather than on science) to support this policy: "History... has shown the importance of exceptional scientific leadership." This emphasis on excellence is one of the reasons why the MRC is thought arrogant, but few of the researchers that I met would disagree with the emphasis.

The MRC then goes on in its plan to accept that this emphasis on excellence will inevitably mean concentrating resources in certain disciplines. But it also says in the next paragraph, "It is not possible to 'opt out' of an area of medical care as a strategy to meet declining resources: there is no sick patient who is not a priority." Faced with this dilemma the council responds by saying: "Priorities in the allocation of resources for research must depend upon excellence and originality, whatever the subject, and the only strategy to follow at a time of declining resources is to raise the threshold for gaining support." This seems to mean that inevitably the MRC will "opt out" of certain topics in medical research, only it will do this in a reactive rather than a directive way. But does this fit with the government's enthusiasm for managing research? Something will have to give.

The MRC's next priority is that teaching and research should go on side by side, a priority that most teachers in medical schools seem to accept. "The best medical practice," says the corporate plan, "is taught to students in an atmosphere where research is also conducted, where current practice is continually questioned, and where the improvement of methods of medical care is seen to be an essential aim." Again the need to concentrate research resources, which is widely accepted, is militating against this concept.

The Advisory Board for the Research Councils's proposal that many British universities (probably most) will not do internationally competitive research conflicts with the MRC's priority, and its report contains a sentence that almost contradicts the MRC: "Experience in North America suggests that the departments with the best reputation for undergraduate training may not be those with the largest and most prestigious research schools." Again what interests me is that one scientific body states the fact that teaching and research must go together as if it is a self evident truth, while another says that "experience ... suggests" that this may not be so. Surely here is another subject for investigation.

Another of the MRC's priorities is training, and few would disagree that "research can prosper only if there is a continual flow of talented recruits into it." But even here the MRC is under pressure because the government is forcing it to reduce its support for undergraduate training in research because the research councils do not have a statutory responsibility for undergraduate training. ${ }^{13}$ The MRC has also had to cut down on studentships for postgraduates.

Well down the list of its priorities-from the government's point of view-the MRC mentions commercial exploitation of research. This has not been a high priority for the MRC and nor has it been for medical researchers. Biotechnology in particular has enormous commercial potential, but British researchers whom I spoke to were 
more interested in publishing than patenting and in pursuing their clinical research than in exploiting what had already been discovered.

Finally, in its corporate plan the MRC mentions the "evaluation of new medical procedures for both safety and efficiency." This important aspect of research does not get much mentioned higher up the research management structure; this may be because it is sometimes almost "anticommercial"-you spend a lot of money proving that a new or existing technique or drug (which might be profitable or might have great commercial potential) is actually useless.

\section{Other views on reasons for doing research}

Most of the medical researchers I met would support the MRC's reasons for doing research and its priorities, which is not surprising because-as it constantly emphasises-the MRC is the medical scientific community. Its council, boards, and grant giving committees are made up almost entirely of medical researchers. It is medical researchers who set the priorities for medical research and who turn down the grant proposals of other medical researchers.

One distinguished researcher who has given his reason for supporting research is Sir Christopher Booth, the director of the Clinical Research Centre. He is characteristically straightforward:

Why is there a need for clinical research? So far as the nation is concerned support for basic scientific research is an obvious requirement and is very easy to justify in view of the extraordinary success of British biologists in winning Nobel prizes. The distinction between basic and clinical or applied research, however, is a sterile debate. As Pasteur put it, "Il n'existe pas des sciences appliquées, mais seulement les applications de la science."

We need clinical research for four main reasons. Firstly, as part of the life sciences it contributes to the overall body of scientific knowledge from fundamental studies of man in health and disease. Secondly, it develops and applies advances in the basic sciences and in technology to the effective investigation and treatment of disease. Thirdly, clinical research has the responsibility of maintaining a constant assessment of both new and existing methods of clinical practice. Finally, it ensures that teaching at both undergraduate and postgraduate level does not degenerate into dogma. ${ }^{14}$

To somebody like me who has been immersed in what the new managers of science want to do Sir Christopher is refreshingly old fashioned in putting knowledge for its own sake at the top of his list and not mentioning commercial applications. But he is also rather naughty and clever. For instance, basic scientific research is not an "obvious requirement" to the Treasury, which cannot find evidence of a direct relation between the amount spent on basic research and the health of the nation's economy. Sir Christopher's justification of basic research in terms of the number of Nobel prize winners that Britain has had may be shortsighted because the number is dropping, and the quoting of Pasteur to dismiss the difference between applied and basic science is to slide round an important question for those who must decide where to spend the nation's limited research budget.

\section{My reasons for why research should be done}

Despite my criticisms of Sir Christopher, when I sat down on a train almost a year ago (before reading much of what I have since read) to think up my reasons for supporting medical research I came up with a list similar to his. My first thought was that it is much easier to make a case for doing medical research than for doing, say, high energy physics: when so much is not known about health and disease research must be done to try to relieve suffering. Nobody needs to justify the search for an AIDS vaccine, but at the same time many people would argue that some of the money spent on the vaccine might better be spent on, for instance, behavioural research.

My second reason for doing medical research-and to me very important-is to evaluate both new and existing treatments. What is interesting about this sort of research, which is one part of health services research, in the light of the Advisory Board for the Research Councils's proposals to concentrate high quality research in certain institutions is that it is not such creative research and does not need the sort of scientists who win Nobel prizes. It might therefore go on in those "downgraded" institutions and might then ensure that students are taught in a questioning environment-because my third reason for doing research was "to keep the brains alive." The articles that I wrote on prison medicine showed me an environment where almost no research was done, and the result was terrible to behold. The snag with doing evaluative research in the "downgraded" institutions is that it may be terribly expensive-look at the MRC's trial on treating mild hypertension.

My fourth reason for doing medical research was the academic one of simply finding out more about the world, and the fifth was to arrive at innovations with commercial potential. Although $\mathrm{Sir}$ Christopher might not see much conflict between these two reasons for doing research, the Treasury does. The Treasury is even more powerful than Sir Christopher.

\section{Conclusions}

The government bodies that set science policy, the bodies that fund it, and the researchers who do it arrange their reasons for doing research in different orders. For the government the main reasons for doing research are to improve defence capability and to make the country more wealthy. These are low priorities to researchers, most of whom are simply driven on to understand further the problem they are tackling. This may or may not have economic potentialoften it will not.

The importance of the different priorities is that as the government struggles to reset research priorities it may irreversibly alienate the people who do the research. And you cannot do research without researchers, or perhaps the government's belief is that you can do without today's researchers and train a new (more domesticated?) breed.

\section{References}

1 Medical Research Council. Corporate plan. London: MRC, 1986.

2 Anonymous. Don't read this. Economise 1987 August 1:86.

3 Ziman J. Changing the form root and branch. Guardian 1987 July 31:20.

4 House of Lords Select Committee on Science and Technology. Civil reseanch and development. Vol 1. London: HMSO, 1986.

5 Civil research and development. Gooernment response to the House of Lords Select Commituee on Science and Technology. 1986-87 session. London: HMSO, 1987.

6 Cabinet Office. Annwal review of gooemment funded RED. London: HMSO, 1986.

7 Office of Health Economics. Crisis in research. London: OHE, 1986.

8 Ronayne J. Science in govermineme. Londion: Edward Arnold, 1984.

8 Ronayne J. Science in govemment. Londion: Edward Arnold, 1984. Organisation for Economic Co-operation and Development.
rechnical activisies. (Frascati manual). Paris: OECD, 1981.

10 Advisory Board for the Research Councils. Science and Public Expenditure. London: ABRC, 1986. 11 Advisory Board for the Research Councils. A stratezy for the science base. London: ABRC, 1987. 12 Irvine J, Martin BR. Foresight in science: picking the wivners. London: Frances Pinter, 1984. 13 Smith R. A senseless sacrifice: the fate of intercalated degrees. Br Med $\mathcal{Y} 1986 ; 292: 619-20$.

14 Booth CC. Doctors in science and society: essays of a clinical scientist. London: British Medical Journal, 1987. 